\title{
COMPARISON OF ANALYTICAL HIERARCHY PROCESS AND FUZZY METHOD IN DEFORESTATION RISK ZONING
}

\author{
M. Pir Bavaghar ${ }^{1 *}$, H. Ghazanfari ${ }^{1}$, Sh. Rahimi ${ }^{2}$ \\ ${ }^{1}$ ITU, Faculty of Natural Resources and The Center for Research \& Development of Northern Zagros Forests, \\ University of Kurdistan, Sanandaj, I.R. Iran - (m.bavaghar, hedayat)@uok.ac.ir \\ ${ }^{2}$ M. Sc. Forestry, Faculty of Natural Resources, University of Kurdistan, Sanandaj, I.R. Iran - sheaida.rahimi@yahoo.com
}

KEY WORDS: Geographic information system, Landsat, Multi-criteria decision-making

\begin{abstract}
:
Detection and prediction of land-cover changes are powerful tools in natural resources management and ecosystem assessment. This study was carried out to compare multi-criteria decision techniques (AHP and fuzzy) in deforestation risk zoning. The TM images of Landsat 5 were used to produce deforestation map during 1989 to 2011. In the next step, the most important criteria affecting deforestation were determined. The final weights of criteria were computed using expert's judgments, pairwise comparisons by AHP and also linguistic terms by fuzzy technique. Weighted linear combination method was used to combining the criteria, and each of the generated maps with its special weight was integrated into the GIS environment. The final deforestation risk zoning map, in both methods of AHP and fuzzy, were classified into five classes including of very high, high, moderate, low and very low risk. Evaluation of the results showed that 81.07 and 80.65 percentages of deforestation are located in the very high and high risk zones in the maps derived from AHP and fuzzy approaches, respectively. Based on the results, AHP and fuzzy methods have suitable performance in deforestation risk zoning. Thus, despite the different nature of the AHP and fuzzy methods, it was observed that these two methods do not have much difference in deforestation risk zoning of the study area, in practice.
\end{abstract}

\section{INTRODUCTION}

Local people living in Zagros forests (the western part of Iran) are largely dependent on the forest for their livelihood, as the majority of people covers their directly (construction timber or cord wood) or indirectly (livestock grazing) economic needs through forest areas. This dependency affects the amount and type of forest exploitation in different parts of Zagros (Ghazanfari et al., 2005). The mentioned activities, in the absence of proper management, can affect the stability of forests.

Mapping land cover/use changes and conducting land capability assessments are essential steps in the management of natural resources and provide an important information source to develop the fundamental policy for the formulation of development plans (Shataee and Abdi, 2007). A lot of research has been done in connection with the consideration of changes in forest cover (Arekhi, 2011; Hoseinzadeh et al., 2013).

Due to extensive changes in land-use and deforestation in recent years, forest mapping, zoning and the investigation of changes becomes increasingly important. Information about these hazards is therefore essential for assessing the socioeconomic and environmental effects of resource management (Biswas et al., 2012). Indeed, the hazard zoning is performed in order to map degradation and changes and estimate the potential influential factors. Hazard zoning provides the possibility to identify vulnerable areas and to consider them in the environmental program (Mas et al., 2004; Phua and Minoua, 2005; Bagheri and Shataee, 2010; Arekhi 2011; Vivien et al., 2011).

To produce a risk zonation map, identifying sites susceptible to hazards through comparing detailed properties of a study area with those of hazard-affected areas, is the direct mapping method. The indirect mapping method involves integrating many influencing factors and using Multi-Criteria DecisionMaking (MCDM) methods, based on the experience of the experts (Lei and Jing-feng, 2006; Feizizadeh and Blaschke, 2013).

MCDM including the use of hierarchical systems of criteria and indicators, provides an efficient tool for addressing and analyzing complex resource issues (Phua and Minoua, 2005; Asgharpour, 2010; Vivien et al., 2011; Biswas et al., 2012; Bharat et al., 2013; Kanga et al., 2013; Liaghat et al., 2013). Analytical hierarchy process (AHP) is one of the most efficient methods of MCDM that could solve the issue based on a hierarchical structure (Akinci et al., 2013; Kanga et al., 2013; Liaghat et al., 2013). This process is designed to provide a structure and framework for collaboration in decision-making and derive preferences for a set of criteria (Saaty, 1995), including the case of natural resources policy (Steiguer et al., 2003, Biswas et al., 2012). AHP has been used in many studies for assigning weights to multiple expert preferences in relation to various criteria (Vargas and Zahedi, 1993; Garfi et al., 2011). Fuzzy logic was applied to act under uncertainties. Fuzzy approaches are a useful tool in the evaluation and decisionmaking due to the formulation of human knowledge in mathematics (Vivien et al., 2011). A Geographic information system (GIS) is applied to manage, analyze and model spatial data and processes. The majority of data in natural resources has a spatial nature, and thus, GIS could be a powerful graphical and analytic tool for managing and modelling this spatial information.

The combination of GIS and MCDM (GIS-MCDM) provides an appropriate collection of techniques and procedures for structuring, evaluating, weighting and prioritizing alternative

\footnotetext{
* Corresponding author
} 
criteria to obtain needed information for decision-making (Malczewski, 2006).

In Zagros forests, one of the most sensitive forest of Iran, forest policy and management is becoming increasingly necessary for sustainable management of natural resources. So, the purpose of this study is to determine changes in forest area over a period of 22 years, prioritize deforestation risk areas, and evaluate the performance of AHP and fuzzy methods in deforestation risk zonation mapping.

\section{MATERIAL AND METHODS}

\subsection{Study area and data}

The study area covers an area of 2686.05 hectares, located 10 $\mathrm{km}$ east of the city of Marivan in Kurdistan Province, Iran. The coordinate of the study area is in WGS1984 UTM Zone $38 \mathrm{~N}$ as follows: $618317 \mathrm{E}$ to $629167 \mathrm{~N}$ and $3930262 \mathrm{E}$ to $3934952 \mathrm{~N}$ (Figure 1).

The two dates of multi-temporal Landsat 5 Thematic Mapper (TM) imagery was used in this study. The 20 June 1989 TM image of the study area was used to generate the initial forest map, and the 19 June 2011 TM image was used to produce the end of the period forest map.

In addition, the digital thematic-topographic maps in scale of 1: 25,000 in WGS1984 UTM Zone 38N coordinate system were used to investigate geometric accuracy of satellite images, producing ground truth map and extraction of the desired map layers.

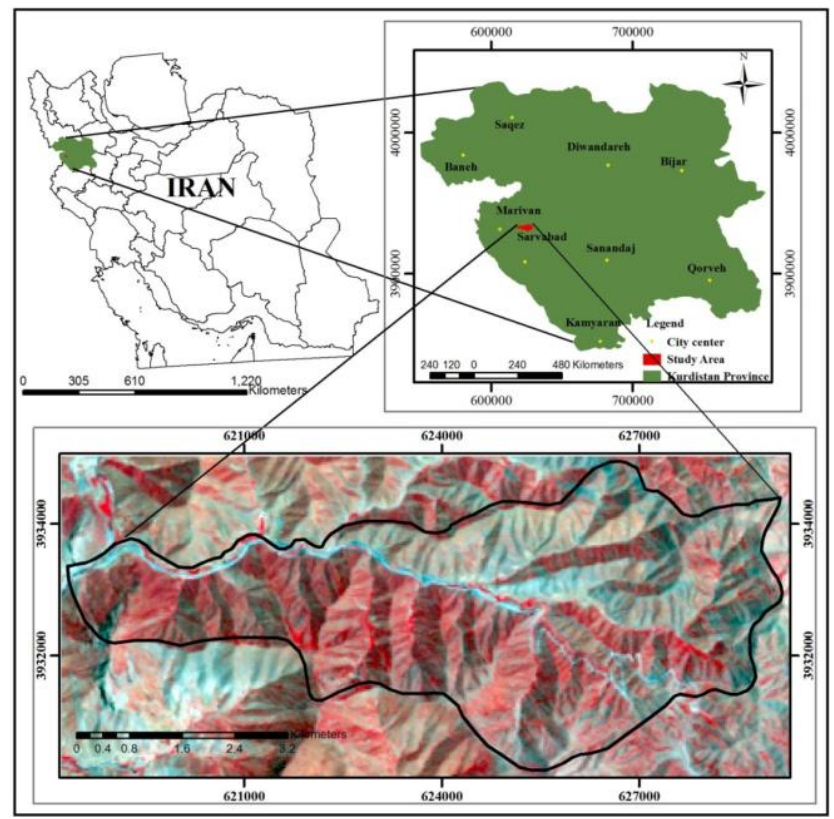

Figure 1. Location of the study area in Iran (a), Kurdistan province (b), and the color-composite (Band 4, 3,2) of Landsat 5 TM imagery (c) of the study area

\subsection{Extracting forest map from satellite imagery}

Satellite images were downloaded from the internet site of United States Geological Survey (USGS), at L1T correction level (terrain corrected level). In order to better extraction of information from satellite images, some processing such as spectral rationing, producing of vegetation indices and principal component analysis was performed on the images. The normalized difference vegetation index (NDVI) and soiladjusted vegetation index (SAVI) were used in this study.
Principal component analysis (PCA) also was undertaken to all the bands, and the first two components were used for classification.

In the next step, training samples with good distribution were selected in forest and non-forest areas, according to the homogeneity of classes, and through field observation. These samples show all the characteristics and conditions are available in two classes. The separability of the samples area was controlled using qualitative (signature comparison chart) and quantitative (transformed divergence) methods, and samples with minimal overlap were selected.

In this study, supervised classification with maximum likelihood algorithm was used, and the forest map of the beginning and end of period was generated.

For generating the ground truth map, referring to the area of each class (forest, non-forest), 65 points was recorded by the GPS device. The Ground truth data were used to evaluate the results maps.

\subsection{Criteria mapping}

Different criteria from internal and external sources have been used, by literature review and library studies. Then, due to the different nature of the criteria, expert views, experiences of research center and according to the application of the results, the most influencing criteria on deforestation were determined. After determining criteria, for each of the determined criteria, a proper map was produced in GIS. For mapping criteria, base maps were prepared using thematic- topographic digital map in the scale of 1: 25,000. Digital elevation model, slope and aspect maps were derived from topographic maps. Maps of residential areas, agriculture and gardens, roads and drainage were also extracted of the digital thematic-topographic maps and the distance of this factors were produced using GIS.

\subsection{Criteria weighting and prioritization \\ 2.4.1 Criteria weighting using analytical hierarchy process}

Selected criteria were weighted and prioritized using analytical hierarchy process. In order to the comparison of criteria the questionnaire was designed and put in the hands of the relevant experts. The importance of the criteria was determined through pairwise comparison. AHP uses a 1-9 scale for comparing. To compare each pair of the criteria, a specific value from 1 to 9 (1 for equal importance and 9 for Extreme importance) was assigned to each pair. The assigned values imported to the Expert Choice software and the local priority (weight) of each criterion was calculated. The consistency ratio (CR) of the comparisons was also evaluated. If the CR is equal to or less than 0.1, the comparison is consistence, otherwise the questionnaires were returned to be revised. Then to integrate the views of all experts, the geometric mean and the final weight was determined for each criterion.

\subsubsection{Criteria weighting using Fuzzy method}

In fuzzy logic, the linguistic variables are used. Linguistic variables are expressed based on the values of language (spoken) in a phrase (words / sentences).

The Fuzzy set introduces the degree of member dependency of a set, and the membership degree of the set members is continuese real numbers between zero and 1 . The closer the grade of membership to 1 indicates more dependency to the set and the closer to zero indicate the low dependency to fuzzy set 
(Wang and Hall, 1996; Vivien et al., 2001). The concept of membership function is of particular importance in the theory of fuzzy sets, because all the details of a fuzzy set described by its membership function and is used for all applications and issues of fuzzy theories.

Determining the membership function, in theory and in practice is very flexible including linear functions, S-shape, triangular, rectangular and trapezoid, that in this study, triangular function was used.

To use fuzzy method and obtain expert view, questionnaire for was designed. In the questionnaire, for each criterion, only one question has been proposed. Since the answers of the questions was in qualitative form with seven option from extremely important to non-important; so to convert these qualitative phrases to definite quantitative numbers, a triangular fuzzy number was assigned to each of the option (Table 1).

Fuzzy numbers with triangular membership function which is used in this research in order to fuzzification the evaluations are shown in Figure 2 and the form of $\tilde{\mathrm{n}}=(\alpha, \mathrm{m}, \beta)$. The mathematical form of the membership function shown in Equation 1.

Triangular membership function is specified by three parameters $\{\mathrm{a}, \mathrm{M}, \beta\}$ as follows:

$$
\mu \tilde{n}(x)=\left[\begin{array}{cc}
\frac{\mathrm{x}-\alpha}{\mathrm{M}-\alpha} & \alpha \leq \mathrm{x} \leq \mathrm{M} \\
\frac{1}{\mathrm{x}-\alpha} & \mathrm{x}=\mathrm{M} \\
\frac{\mathrm{M}-\beta}{\mathrm{M}} & \mathrm{x} \leq \beta
\end{array}\right]
$$

Triangular numbers have a membership function that includes the two L (left) and R (right) linear parts that are connected at the head $(1 \mathrm{M})$. The reason for using triangular fuzzy numbers is its simple calculations and ease of use to decision makers.

Then, using fuzzy logic concepts and Yaeger formula, defuzzification was done (Facchinetti et al., 1998; Bevilacqua and Ciarapica, 2006).

$$
(\alpha, \mathrm{m}, \beta)=\frac{\alpha+(2 \mathrm{~m})+\beta}{4}
$$

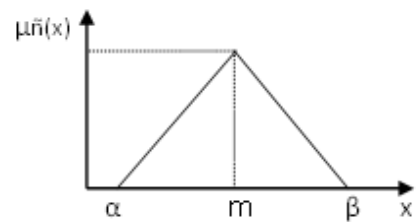

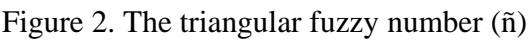

Table 1. Linguistic variables and fuzzy numbers for the importance weight (Lin et al., 2006)

\begin{tabular}{lc} 
Linguistic variables & $\begin{array}{c}\text { Fuzzy numbers } \\
(\alpha \cdot \mathrm{m} \times \beta)\end{array}$ \\
\hline Very High & $(0.85,0.95,1)$ \\
High & $(0.7,0.8,0.9)$ \\
Fairly High & $(0.5,0.65,0.8)$ \\
Medium & $(0.3,0.5,0.7)$ \\
Fairly Low & $(0.2,0.35,0.5)$ \\
Low & $(0.1,0.2,0.3)$ \\
Very Low & $(0,0.05,0.15)$ \\
\hline
\end{tabular}

\subsection{Standardization of Criteria}

For integrating the map layer of criteria, the scales must be in proportion to each other, so the standardization of criteria was done. A linear scale transformation based on a maximum score (Equation 3), is used for standardization of the criteria with the purpose of converting to the scale 0.0 to 1.0. Whatever the value of the score is closer to 1 , the suitability of the criterion will be higher (Malczewski, 1999).

$$
\text { (3) } \quad \mathrm{Xij}_{\mathrm{ij}}=\frac{\mathrm{x}_{\mathrm{ij}}}{\mathrm{x}_{\mathrm{j}}^{\max }}
$$

$\mathrm{Xij}$ : the standardized score of the respective variable

$x i j$ : The original value of the respective variable

$$
x^{\max }: \text { The maximum value of the respective variable }
$$

\subsection{Criteria Integration and deforestation risk zoning}

Weighted linear combination (WLC) based on weighted mean, is the most common technique in multi-criteria decision making issues. In this method the weight of each criterion multiplied by its standardized score and then summed the results over all criteria (Malczewski, 1999). So, the deforestation risk zone map was produced. Based on the final scores, this map was classified to 5 deforestation risk classes (0.84 - 1 very high danger, 0.68 - 0.84: high danger, 0.52 - 0.68: medium danger, $0.52-0.36$ : low danger and lower than 0.36 : very low danger).

\subsection{Accuracy assessment of deforestation risk zoning}

During the process of accuracy assessment, the truth deforestation map was compared to deforestation risk zoning produced by AHP and fuzzy methods.

\section{RESULTS}

\subsection{Forest area maps}

The best results of classification with overall accuracy of $94.62 \%$ and kappa coefficient of 0.89 was used to produce forest area map of the year 2011. Forest/non-forest map for the year 1989 was generated with $87.74 \%$ overall accuracy and 0.79 kappa coefficient.

\subsection{Forest area change detection}

Forest area change detection map (Figure 3) was produced by subtracting the recent forest area map (2011) from the earlier map (1989). This map includes only forest degradation.

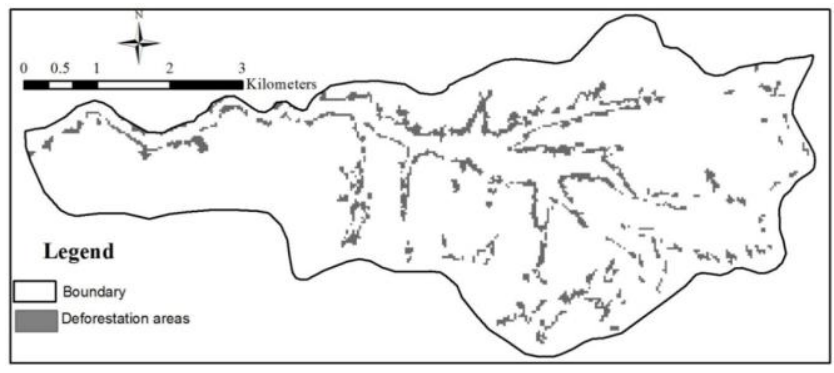

Figure 3. Deforestation map during 1989-2011 


\subsection{Criteria weighting and prioritization}

The results of criteria weighting and prioritization using analytical hierarchy process showed that, the distance from residential areas with the weight of 0.358 is the most important criterion and aspect with the value of 0.028 has the lowest important priority in deforestation (table 2). The consistency ratio $(\mathrm{CR})$ of the comparisons was 0.06 , so the comparison was consistence.

Table 3 shows the results of conversion of the triangular fuzzy numbers to crisp scores by Yaeger formula. It should be noted that the use of different conversion scales for the same linguistic variables may lead to different crisp values (Skupiene, 2011).

The mean of each criterion weight is illustrated in table 4, according to frequency of experts' answers in each of the criteria and the calculated crisp value for each of the linguistic variables.

Table 2. Conversion of triangular fuzzy numbers to crisp scores using Yaeger formula

\begin{tabular}{|c|c|c|}
\hline $\begin{array}{l}\text { Linguistic } \\
\text { variables }\end{array}$ & $\begin{array}{c}\text { Triangular } \\
\text { fuzzy } \\
\text { numbers } \\
(\alpha, \mathrm{m}, \beta)\end{array}$ & $\begin{array}{l}\text { Crisp } \\
\text { score }\end{array}$ \\
\hline $\begin{array}{l}\text { Very } \\
\text { High }\end{array}$ & $(0.85,0.95,1)$ & 0.94 \\
\hline High & $(0.7,0.8,0.9)$ & 0.80 \\
\hline $\begin{array}{c}\text { Fairly } \\
\text { High }\end{array}$ & $(0.5,0.65,0.8)$ & 0.65 \\
\hline Medium & $(0.3,0.5,0.7)$ & 0.50 \\
\hline $\begin{array}{l}\text { Fairly } \\
\text { Low }\end{array}$ & $(0.2,0.35,0.5)$ & 0.35 \\
\hline Low & $(0.1,0.2,0.3)$ & 0.20 \\
\hline $\begin{array}{l}\text { Very } \\
\text { Low }\end{array}$ & $(0,0.05,0.15)$ & 0.06 \\
\hline
\end{tabular}

Table 3. Priorities calculated by pairwise comparison of the criteria which influence deforestation

\begin{tabular}{llll}
\hline Criteria & Weight & Criteria & Weight \\
Distance from residential areas & 0.358 & Slope & 0.053 \\
$\begin{array}{l}\text { Distance from agriculture and } \\
\text { gardens }\end{array}$ & 0.210 & Elevation & 0.047 \\
$\begin{array}{l}\text { Distance from roads } \\
\text { Distance from drainage }\end{array}$ & 0.202 & Aspect & 0.028 \\
\hline
\end{tabular}

\subsection{Deforestation risk zoning using analytical hierarchy process and fuzzy method}

Figure 4 and 5 show deforestation risk zoning in 5 risk classes derived from analytical hierarchy process and fuzzy method, respectively.

\subsection{Comparison of real deforestation map with the deforestation risk zoning maps derived from analytical hierarchy process and fuzzy method}

Table 5 shows the results of the real deforestation areas in each zone of deforestation risk map derived from AHP and fuzzy method.

Accuracy assessment results showed that, $60.19 \%$ and $44.37 \%$ of the study area are located in very high deforestation risk zone in AHP and fuzzy method, respectively (Table 5). This indicated that AHP method is the most efficient method for deforestation risk zoning. However, $81.55 \%$ and $80.61 \%$ of the study area are located in the very high and high risk zones in AHP and Fuzzy method, respectively, so there isn't much difference between two methods.

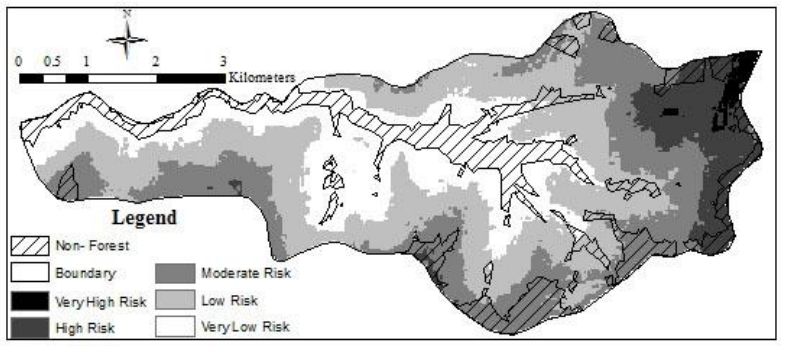

Figure 4. Deforestation risk zoning using analytical hierarchy process

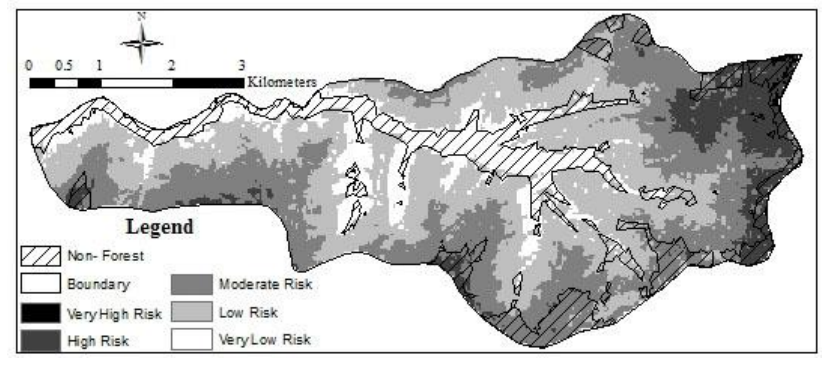

Figure 5. Deforestation risk zoning using fuzzy method

Table 4. The weight of each criterion through crisp scores of fuzzy method

\begin{tabular}{|c|c|c|c|c|c|c|c|c|}
\hline \multirow[t]{3}{*}{ Criterion } & \multicolumn{7}{|c|}{ Frequency of experts answers in each linguistic variables } & \multirow{3}{*}{$\begin{array}{l}\text { The mean of } \\
\text { weight } \\
\text { (Defuzzified } \\
\text { scores) }\end{array}$} \\
\hline & 1 & 2 & 3 & 4 & 5 & 6 & 7 & \\
\hline & 0.94 & 0.8 & 0.65 & 0.5 & 0.35 & 0.20 & 0.6 & \\
\hline $\begin{array}{l}\text { Distance from } \\
\text { residential areas }\end{array}$ & 5 & 3 & 2 & - & - & - & - & 0.840 \\
\hline Distance from roads & 1 & 2 & 5 & 2 & - & - & - & 0.679 \\
\hline $\begin{array}{l}\text { Distance from } \\
\text { agriculture and gardens }\end{array}$ & 4 & 3 & 2 & - & 1 & - & - & 0.781 \\
\hline Distance from drainage & 1 & 1 & 2 & 4 & 2 & - & - & 0.574 \\
\hline Slope & - & 2 & 1 & 5 & 2 & - & - & 0.545 \\
\hline Aspect & - & - & 1 & 4 & 4 & 1 & - & 0.425 \\
\hline Elevation & - & 1 & 3 & 4 & 2 & - & - & 0.545 \\
\hline
\end{tabular}


Table 5. The results of the real deforestation areas in each zone of deforestation risk map

\begin{tabular}{ccccc}
\hline $\begin{array}{c}\text { Importance } \\
\text { degree }\end{array}$ & \multicolumn{2}{c}{ Fuzzy method } & \multicolumn{2}{c}{ AHP } \\
$\begin{array}{c}\text { Area } \\
(\%)\end{array}$ & $\begin{array}{c}\text { Area } \\
(\text { Hectare) }\end{array}$ & $\begin{array}{c}\text { Area } \\
(\%)\end{array}$ & $\begin{array}{c}\text { Area } \\
(\text { Hectare })\end{array}$ \\
$\begin{array}{c}\text { Very high } \\
\text { danger }\end{array}$ & 44.37 & 92.53 & 60.19 & 125.52 \\
$\begin{array}{c}\text { high } \\
\text { danger }\end{array}$ & 36.24 & 75.57 & 21.36 & 44.55 \\
$\begin{array}{c}\text { Medium } \\
\text { danger }\end{array}$ & 14.90 & 31.08 & 13.23 & 27.60 \\
$\begin{array}{c}\text { Low } \\
\text { danger }\end{array}$ & 4.36 & 9.09 & 4.91 & 10.24 \\
$\begin{array}{c}\text { Very low } \\
\text { danger } \\
\text { Sum }\end{array}$ & 0.13 & 0.27 & 0.30 & 0.63 \\
\hline
\end{tabular}

\section{DISCUSSION}

Detecting deforestation risk zoning is parts of the forest change detection study process that various methods are available for prioritizing of the risk areas. In this case, MCDM techniques have been used for helping decision-makers to produce deforestation risk zoning. These techniques could generally assist decision-makers and natural resources managers to develop functioning models of sustainable development (Biswas et al., 2012).

There are different driving factors of deforestation. These factors in addition to their different nature also have various effects from one to another site. Therefore, using literature review (Gruenberg et al., 2000; Mas et al., 2004; Bagheri and Shataee, 2010; Hosseinzadeh et al., 2013; Munthali and Murayama, 2015) and the condition of region, some of the effective and important factors including physiographic factors (slope, Aspect, elevation), distance from residential, agriculture and gardens, roads, and drainage as the driving factors to deforestation are studied in this research.

The use of MCDM for weighting and prioritizing the criteria is a challenging and time-consuming work due to the lack of familiarity of experts with the ranking/rating in AHP method (Biswas et al., 2012). Nevertheless, it seems appropriate to solve complex environmental problems.

The results of the pairwise comparison of AHP, and fuzzy method showed that among influencing factors on deforestation, distance from residential areas, and distance from agriculture and gardens have the most weight and priority, and aspect has the lowest importance and priority. According to Munthali and Murayama (2015), the deforestation reduces, spatially, as distance from road, river, and forest/settlement edges increases. Hosseinzadeh et al. (2013) using logistic regression concluded that the distance from rural areas is the most influencing factors in deforestation, due to supply of fuel consumption and the expansion of arable areas. According to Sakthivel et al. (2010), the intensity of agriculture and other rural activities are the most important factors in deforestation.

The evaluation of the risk of deforestation zoning using AHP showed that the areas with very high risk and high risk are included the most of the study area. These areas are located in the flat, gentle slope areas with low elevation and also with a proper access to communication roads. Most of the agricultural and horticultural areas, major drainage and all of the residential areas are scattered in these regions.
The results of accuracy assessment of deforestation risk zoning produced by AHP and fuzzy method showed that the significant areas of deforestation in zonation map are located in the areas with very high and high risk of deforestation. These results confirm the efficiency of the multi-criteria decision-making in deforestation risk zoning in northern Zagros forests of Iran. Kanga et al. (2013) are mentioned to the same results of AHP and fuzzy method in forest fire risk zoning that is in agreement with our results.

Questionnaire that will be provided to relevant experts is a tool for data gathering in multi-criteria decision making. AHP usually need special care, because weighting and prioritizing of criteria are based on pairwise comparison, while the other criteria also must be considered. In some cases, lack of attention to reverse law of comparisons and the lack of adequate attention to completing the questionnaires, leading to increased rates of inconsistency and therefore returning of the questionnaires to experts for revision. Sometimes this happens several times, which is a time consuming process. On the other hand, the possibility of formulating a hierarchy issues, taking into account qualitative and quantitative criteria and pairwise comparisons between criteria, are some of the strengths of AHP.

In the fuzzy method, contrary to hierarchical analysis, formulating the uncertainty related to experts view is possible. In this method, linguistic variables are used for weighting the criteria and the criteria priority will be determined in one step that is understandable to all people, so there will not be errors in filling out the questionnaires, generally. But, the important point in Fuzzy approach is the use of a different range of defuzzification of the linguistic variables, that incorrect selection of model (false fuzzy numbers) and improper membership function could lead to reduced accuracy of the results. These methods of zonation mapping depend mainly on the weights assigned to the parameters responsible for different hazards (Ghosh et al., 2012).

\section{CONCLUSION}

This study was carried out to compare multi-criteria decision techniques (AHP and fuzzy) in deforestation risk zoning. Based on the results, AHP and fuzzy methods have suitable performance in zoning the risk of deforestation. Thus, despite the differences in implementation of these two methods, acceptable results were obtained by applying both of two methods.

\section{REFERENCES}

Akinci H, Ozalp AY, Turgut B. 2013. Agricultural land use suitability analysis using GIS and AHP technique. Comput Electron Agr 97: 71-82.

Arekhi, S., 2011. Modeling spatial pattern of deforestation using GIS and logistic regression: A case study of northern Ilam forests, Ilam province, Iran. Afr J Biotechnol 10(72): 1623616249.

Asgharpour M J. 2010. Multi Criteria Decision Making. University of Tehran, Tehran.

Bagheri R,Shataee Sh. 2010. Modeling forest areas decreases, using logistic regression (case study: Chehl-Chay catchment, Golestan province). Iran J Forest 2(3): 243-252 (article in Persian with an abstract in English). 
Bevilacqua M, Ciarapica FE. 2006. A Fuzzy- QFD approach to Supplier Selection. J Purch Supply Manag 12(1):14-27.

Biswas Sh, Vacik H, Swanson ME, Haque SMS. 2012. Evaluating Integrated watershed management using multiple criteria analysis - a case study at Chittagong Hill Tracts in Bangladesh. Environ Monit Assess 184:2741-2761.

Facchinetti G, Ghiselli Ricci R, Muzioli S. 1998. Note on ranking fuzzy triangular numbers. Int J Intell syst 13: 613-622.

Feizizadeh B, Blaschke T. 2013. GIS-multicriteria decision analysis for landslide susceptibility mapping: comparing three methods for the Urmia lake basin, Iran. Nat Hazards 65: 21052128 .

Garfi M, Ferrer-Marti L, Bonoli A, Tondelli S. 2011. Multicriteria analysis for improving strategicenvironmental assessment of water programmes. A case study in semi-arid region of Brazil. J Environ Manage 92(3): 665-675

Ghosh JK, Bhattacharya D, Sharma SK. 2012. Fuzzy knowledge based GIS for zonation of landslide susceptibility, In: Banerjee S, Mitra M, Rondoni L (ed) Applications of Nonlinear Dynamics and Chaos in Engineering, Vol - II. Springer, pp 21-37.

Gruenberg WD, Curtin P, Shaw W. 2000. Modeling deforestation risks for the Maya biosphere reserve, Guatemala. M. S. thesis, The University of Arizona.

Ghazanfari H, Namiranian M, Sobhani H, Marvi Mohadjer MR, Pourtahmasi K. 2005. An estimation of tree diameter growth of Lebanon oak (Quercus libani) in northern Zagross forests (Case study, Havareh khole). Iran J Nat Res 57(4): 649-662 (article in Persian with an abstract in English).

Hosseinzadeh MM, Derafshi KH, Mirbagheri B. 2013. Modeling forest extent change and its influencing factors, using logistic regression model in GIS environment, (case study: Vaz and Lavij basins). Iran J For. Poplar Res 21 (1): 86-98 (article in Persian with an abstract in English).

Kanga S, Sharma LK, Pandey PC, Nathawat MS, Sharma SK. 2013. Forest fire modeling to evaluate potential hazard to tourism sites using geospatial approach. J Geomatics 7(1): $93-$ 99

Lei Z, Jing-feng H. 2006. GIS-based logistic regression method for landslide susceptibility mapping inregional scale. J Zhejiang Univ Sci A 7(2): 2007-2012.

Lin Ch, Chiu H, Chu P. 2006. Agility index in the supply chain. Int J Prod Econ 100(2): 285-299.

Malczewski J. 1999. GIS and Multicriteria Decision Analysis. John Wiley and Sons, New York.

Malczewski J. 2006. GIS-based multicriteria decision analysis: a survey of the literature. Int J Geogr Inform Sci 20(7): $703-$ 726.

Mas JF, Puig H, Palacio JL, Sosa-Lopel A. 2004. Modeling deforestation using GIS and artificial neural networks. Environ Model Softw 19(5): 461-471.
Munthali KG, Murayama Y. 2015. Modeling deforestation in Dzalanyama Forest Reserve, Lilongwe, Malawi: a multi-agent simulation approach. GeoJournal 80: 743-757

Phua MH, Minowa M. 2005. A GIS-based multi-criteria decision making approach to forest conservation planning at a landscape scale: a case study in the Kinabalu Area, Sabah, Malaysia. Landscape Urban Plan 71(2-4): 207-222.

Shataee Sh, Abdi O. 2007. Landcover mapping in mountainous lands of Zagros using ETM+ data (Case study: Sorkhab watershed, Lorestan province). J Agri sci and Nat Res 14(1): 110 .

Skupiene J. 2011. Score calculation in informatics contests using multiple criteria decision methods, Inform Ed 10 (1): 89103.

Van Kooten GC, Krcmar E, Bulte EH. 2001. Preference uncertainty in non- market valuation: a fuzzy approach. Am J Agr Econ 83 (3): 487-500.

Vargas L, Zahedi F (1993). Analytic hierarchy process and its applications. Mat Comput Model 17(4-5): 1-209.

Vivien YC Ch, Lien H, Liu Ch, Liou JH, Tzeng G, Yang L 2011. Fuzzy MCDM approach for selecting the best environment-watershed plan. Appl Soft Comput 11(1): 265275 .

Wang F, Hall GB. 1996. Fuzzy representation of geographical boundaries in GIS. Int J Geogr Inf Sci 10(5): 573-590. 